\title{
Bone mineral density distribution in early osteoporotic bone
}

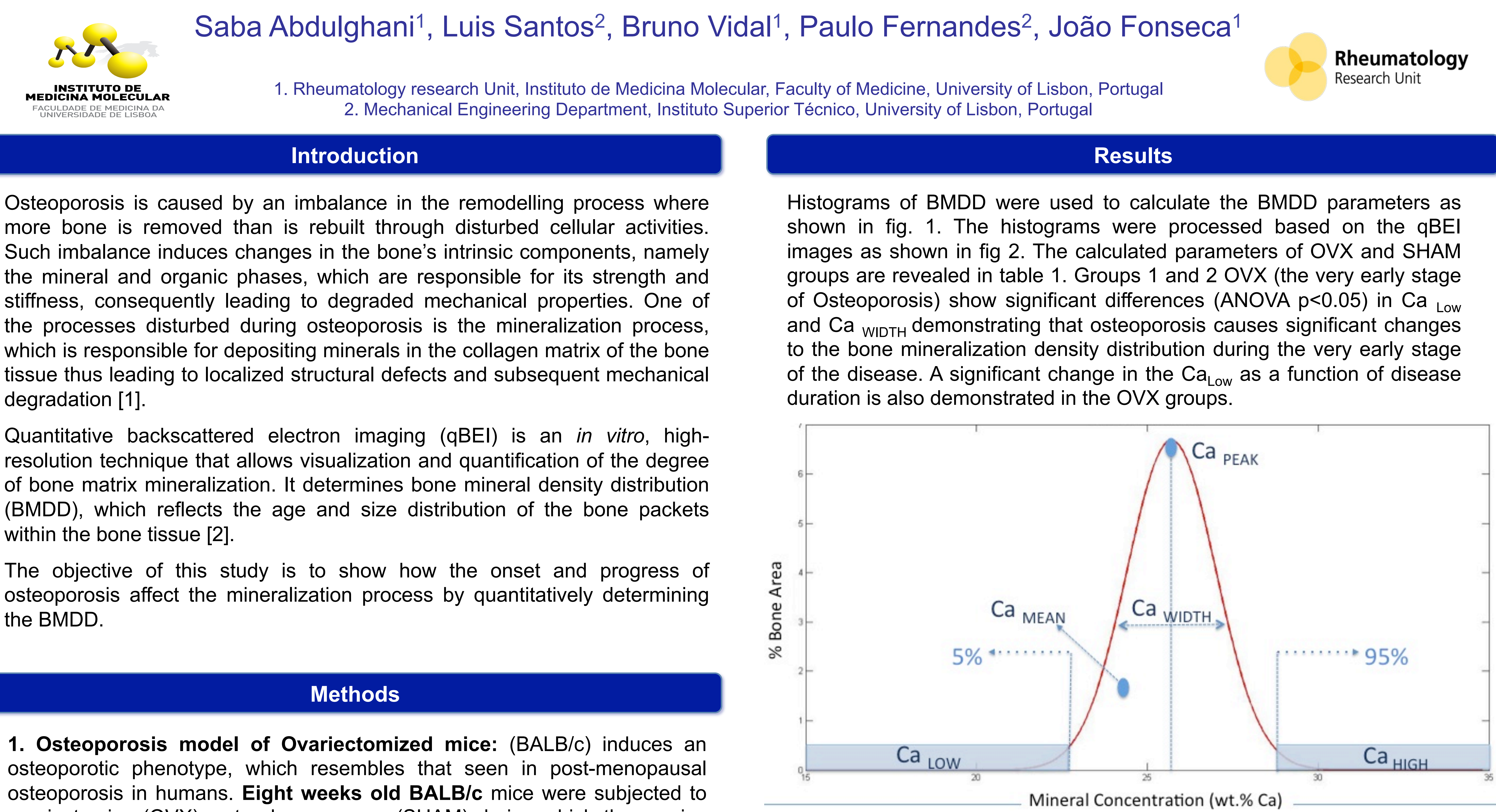
elo ovariectomies (OVX) or to sham surgery (SHAM) during which the ovaries were exteriorised but replaced intact by the operator and thus used as a control group. Lumbar vertebrae (L3) were collected at the time of sacrifice and used for the qBEl study. Six experimental groups were evaluated according to the sacrifice time line, with 5 OVX and 5 SHAM in each as shown below.

\begin{tabular}{l|c|c|c|c|c|c} 
& Group 1 & Group 2 & Group 3 & Group 4 & Group 5 & Group 6 \\
\hline Disease duration & 2 wks & $1 \mathrm{mth}$ & $2 \mathrm{mth}$ & $3 \mathrm{mth}$ & $5 \mathrm{mth}$ & $7 \mathrm{mth}$
\end{tabular}

\section{2. qBEI \& BMDD analysis:}

qBEI was performed using a Scanning Electron Microscope (SEM) fitted with a backscattered detector, using a voltage of $15 \mathrm{kV}$ and a constant magnification of $100 \mathrm{x}$, leading to a resolution of $0.93 \mu \mathrm{m} / \mathrm{pixel}$.

The calibration procedure followed the method outlined by Roschger et al (1998) [2 ], using hydroxyapatite (HA), Magnesium oxide (MgO) and Silicon dioxide $(\mathrm{SiO} 2)$ as reference materials, from which a linear relationship between gray level intensity and calcium percentage was obtained.

A custom MATLAB script was developed to analyze the qBEl images, assigning a calcium percentage to each pixel, according to the calibration procedure. BMDD histograms (resolution: $0.13 \% \mathrm{Ca}$ ) were obtained for each sample and averaged within each group. A Gaussian curve-fit was used to model the histograms and compute BMDD parameters $\left(\mathrm{Ca}_{\mathrm{MEAN}}, \mathrm{Ca}_{\mathrm{PEAK}}\right.$, $\mathrm{Ca}_{\text {WIDTH}}, \mathrm{Ca}_{\text {LOW }}$ and $\mathrm{Ca}_{\text {HIGH }}$ ). Ca Low and $\mathrm{Ca}$ High represent the percentage of bone, in OVX samples, located in the $5^{\text {th }}$ and $95^{\text {th }}$ percentile of SHAM BMDD, for each group.
Histograms of BMDD were used to calculate the BMDD parameters as shown in fig. 1. The histograms were processed based on the qBE of Osteoporosis) show significant differences (ANOVA $p<0.05$ ) in $\mathrm{Ca}$ Low and $\mathrm{Ca}$ WIDTH demonstrating that osteoporosis causes significant changes the bone mineralization density distribution during the very early stage the disease. A significant change in the Ca ow a function of disease duration is also demonstrated in the OVX groups.

Fig. 1 BMDD histogram showning the calculations of the BMDD parameters. $\mathrm{Ca}_{\text {MEAN }}$ is the weighted average $\mathrm{Ca}$ concentration of the mineralized tissue area, obtained from the integrated area under the BMDD curve., $\mathrm{Ca}_{\mathrm{PEAK}}$, the peak position of the histogram, which indicates the most frequently measured calcium concentration ( $\mathrm{Ca}$ value with the highest number of pixels) in the bone, $\mathbf{C a}_{\text {WIDTH }}$ is the width at half-maximum of the BMDD bone area passing primary mineralization, $\mathrm{Ca}_{\mathrm{HIGH}}$, the $\%$ of bone area that is mineralized above the $95 \%$ of the reference range [2] and therefore corresponds to the amount of bone area having achieved full mineralization (reached a plateau level of mineralization).
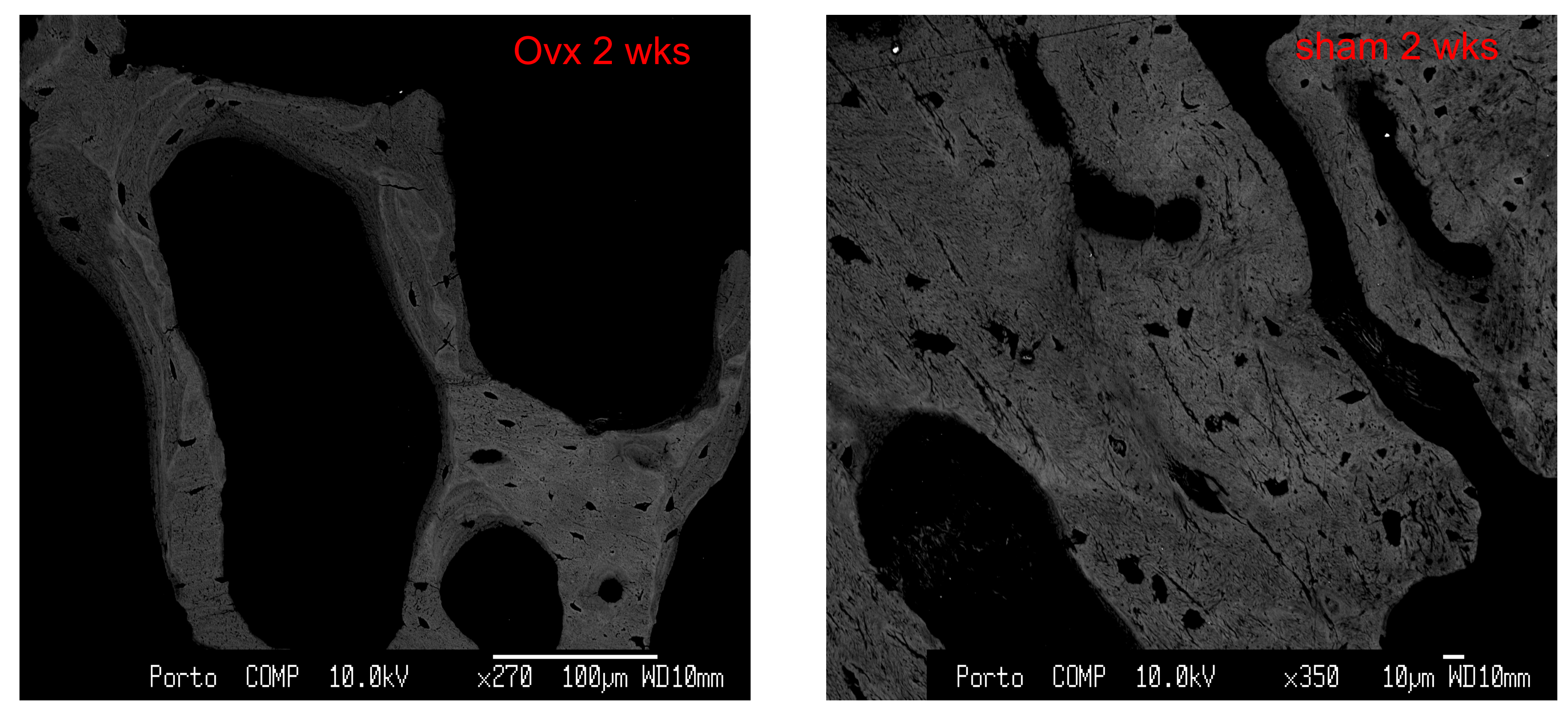

Fig. 2 qBEI grey scale images obtained for OVX and SHAM groups at 2 weeks of disease duration groups are revealed in histogram curve indicating the heterogeneity of mineralization either caused by the coexistence of differently mineralized bone matrix, $\mathrm{Ca}_{\llcorner\mathrm{L}}$, the $\%$ of bone area that is mineralized below the $5 \%$ of the reference range which corresponds to the amount of

Table 1 BMDD calculated parameters for the OVX and SHAM groups during the onset and progress of the disease

\begin{tabular}{|c|c|c|c|c|c|c|c|c|}
\hline Groups & $\begin{array}{r}\mathrm{Ca}_{\wedge} \\
\text { [wt.\% } \\
\text { OVX(STD) }\end{array}$ & $\begin{array}{l}\text { MEAN } \\
\text { \% Ca] } \\
\text { SHAM(STD) }\end{array}$ & $\begin{array}{r}\mathrm{Ca}_{\mathrm{f}} \\
{[\mathrm{wt} . \%} \\
\mathrm{OVX}(\mathrm{STD})\end{array}$ & $\begin{array}{l}\text { PEAK } \\
\text { SHAM(STD) }\end{array}$ & $\begin{array}{r}\mathrm{Ca}_{\mathrm{V}} \\
\text { [wt.\% } \\
\text { OVX(STD) }\end{array}$ & $\begin{array}{l}\text { NIDTH } \\
\text { SHAM(STD) }\end{array}$ & $\begin{array}{c}\text { Ca Low } \\
{[\% \text { bone area] }} \\
\text { OVX }\end{array}$ & $\begin{array}{c}\mathrm{Ca}{ }_{\text {HIGH }} \\
{[\% \text { bone area }]} \\
\text { OVX }\end{array}$ \\
\hline 1 & $25.08 \pm 0.95$ & $24.81 \pm 0.86$ & $25.79 \pm 1.02$ & $25.62 \pm 0.86$ & $3.76 \pm 0.30$ & $4.16 \pm 0.65$ & 4.04 & 9.47 \\
\hline 2 & $24.35 \pm 0.20$ & $24.86 \pm 0.12$ & $25.11 \pm 0.28$ & $25.44 \pm 0.02$ & $3.94 \pm 0.63$ & $3.57 \pm 0.00$ & 7.62 & 5.96 \\
\hline 3 & $24.57 \pm 0.45$ & $24.94 \pm 1.00$ & $25.17 \pm 0.63$ & $25.61 \pm 0.90$ & $3.76 \pm 0.61$ & $4.23 \pm 0.30$ & 4.94 & 4.10 \\
\hline 4 & $24.84 \pm 0.49$ & $25.05 \pm 0.48$ & $25.36 \pm 0.42$ & $25.73 \pm 0.58$ & $3.39 \pm 0.28$ & $3.50 \pm 0.52$ & 4.11 & 4.29 \\
\hline 5 & $25.48 \pm 0.24$ & $25.33 \pm 0.10$ & $26.00 \pm 0.31$ & $25.96 \pm 0.17$ & $2.90 \pm 0.08$ & $2.95 \pm 0.19$ & 4.41 & 10.55 \\
\hline 6 & $25.60 \pm 0.20$ & $25.65 \pm 0.21$ & $26.11 \pm 0.14$ & $26.20 \pm 0.22$ & $3.21 \pm 0.31$ & $3.35 \pm 0.23$ & 5.45 & 7.10 \\
\hline
\end{tabular}

\section{Conclusions}

Our results show that the \% bone area that passes primary mineralization $\left(\mathrm{Ca}{ }_{\text {Low }}\right)$ is significantly altered along the course of the disease as shown in OVX groups 1,2 and 6. Although the other parameters display sever changes, they are not statistically significant and a higher sample number is therefore required for future work. The results of this study for the Ca MEAN and $\mathrm{Ca}$ PEAK are within the range reported by other researchers [1-3]. In conclusion, our study confirms that osteoporosis causes significant changes to the BMDD during the very early stage of the disease manifestation.

\section{References}

1. Gupta HS, Wagermaier W, Zickler GA, Aroush DR, Funari SS, Roschger P, Wagner HD, Fratzl P. Nanoscale deformation mechanisms in bone. Nano Lett 5:2108-11, 2005 Roschger P, Fratzl P, Eschberger J, and Klaushofer K. Validation of quantitative backscattered electron imaging for the measurement of mineral density distribution in human bone biopsies. Bone 23:319-326, 1998.

3. Roschger P, Rinnerthaler S, Yates J, Rodan GA, Fratzl P, Klaushofer K. Alendronate increases degree and uniformity of mineralization in can- cellous bone and decreases the porosity in cortical bone of osteoporotic women. Bone ;29(2):185-91, 2001. The authors declare no conflict of interest in this study. 